\title{
ÁlCOOL E OUTRAS DROGAS E A IMPLANTAÇÃO DA POLÍTICA DE REDUÇÃO DE DANOS NO BRASIL: REVISÃO NARRATIVA
}

\author{
ALCOHOL AND OTHER DRUG AND THE DAMAGE REDUCTION POLICY \\ IN BRAZIL: NARRATIVE REVIEW
}

\author{
Zaira Letícia Tisott $\mathrm{t}^{*}$, Leila Mariza Hildebrand $\mathrm{t}^{\mathrm{b}^{*}}$, Marinês Tambara Leite ${ }^{\mathrm{c}^{*}}$, \\ Ricardo Vianna Martins ${ }^{\mathrm{d}^{*}}$, Susane Flôres Cosentino ${ }^{\mathrm{e}^{*}}$ \\ azairatisott10@gmail.com, bleilahildebrandt@yahoo.com.br, ctambaraleite@yahoo.com.br,

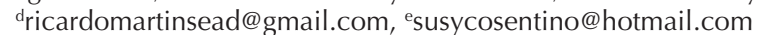 \\ *Universidade Federal de Santa Maria - Palmeira das Missões (RS), Brasil
}

Data de entrada do artigo: 06/05/2014

Data de aceite do artigo: 22/08/2014

\section{RESUMO}

Introduçáo: $\mathrm{O}$ uso de substâncias psicoativas sempre fez parte da história da humanidade, de diferentes formas e em diversos contextos culturais, e as políticas de reduçáo de danos se constituem em estratégias de intervençáo. Objetivo: Analisar artigos publicados on-line em periódicos nacionais, no período de 2006 a 2012, relativos às políticas de redução de danos no Brasil e à maneira como estas vêm sendo implantadas. Método: Trata-se de uma revisão narrativa. A busca bibliográfica foi desenvolvida na Biblioteca Virtual (BVS-Bireme), disponível pela Base de Dados de Enfermagem (BDENF), pela Literatura Latino-Americana e do Caribe em Ciências da Saúde (Lilacs) e pela Biblioteca Virtual Coleção Scientific Eletronic Library Online (Scielo). Foram incluídos na pesquisa artigos originais, com texto na íntegra, disponíveis em suporte eletrônico. Os dados foram analisados seguindo os preceitos da análise de conteúdo temática. Foram selecionados 9 artigos originais, cujas informações foram agrupadas em dois temas. Resultados e discussáo: Destacam-se desafios para a organização e implantação da política de reduçáo de danos, relacionados às equipes de saúde, aos gestores municipais e à sociedade, devidos ao medo, ao preconceito e à falta de interesse pela temática. Notam-se modificaçóes referentes à metodologia de trabalho e a necessidade de discussão acerca da redução de danos em diferentes espaços de atenção. Conclusáo: $\mathrm{O}$ trabalho de redução de danos deve ser realizado por toda a equipe, sendo necessários a corresponsabilização e o protagonismo do usuário de álcool e outras drogas na sua construção.

Palavras-chaves: redução do dano; promoção da saúde; transtornos relacionados ao uso de substâncias.

\section{ABSTRACT}

Introduction: The use of psychoactive substances has always been a part of the humanity history in different ways and in several cultural contexts, and damage reduction policies have been intervention strategies. Objective: To analyze the published articles online in national periodical publications, from 2006 to 2012, about damage reduction policies in Brazil and how they have been implanted. Method: It was used a narrative review of literature. The bibliographic search on the theme was developed at the Virtual Library of Health, available at the Date Base of Nursing and Latin American Literature and Caribbean in Health Sciences and at the Virtual Library Scientific Electronic Library Online Collection. Original articles available online were included in the research. The data were analyzed following the indications of the thematic analysis. They were selected nine original articles for the analysis, whose information were grouped into two themes. Results and Discussion: We highlighted the challenges for the organization and implantation of the damage reduction policy, related to the health teams, municipal directors/managers and society, due to the fear, prejudice and lack of interest on the thematic. The changes concerning the methodologies applied and the need of discussion on the damage reduction in different 
attention spaces were observed. Conclusion: The work must be performed by the whole team,and the co-responsibility and the main role of the user in his construction is necessary.

Keywords: damage reduction; health fostering; disorders related to the use of substances.

\section{Introdução}

O uso de substâncias psicoativas faz parte da história da humanidade, de diferentes formas e em diversos contextos culturais. Alguns povos as tinham em sua cultura com distintas finalidades, como de natureza lúdica, religiosa e terapêutica. Mais tarde, com a descoberta dos fármacos, houve aumento acentuado na busca de substâncias, as quais eram usadas pela população em geral a fim de evitar qualquer tipo de sofrimento. $\mathrm{O}$ uso de drogas não apresentava ameaças à sociedade, pois era feito em rituais coletivos ou orientado por algum objetivo que a sociedade reconhecia como forma de manifestação de sua cultura ${ }^{1}$. Destaca-se que a preocupação com o uso de drogas acentuou-se a partir do advento das doenças transmissíveis, em especial o vírus da imunodeficiência humana (HIV) e a síndrome da imunodeficiência adquirida (AIDS) ${ }^{2}$.

Devido à apreensão e à dimensão do uso de drogas psicoativas hoje, no Brasil, o Ministério da Saúde propóe que o usuário de drogas deve ser visto de maneira integral, com o objetivo de preveni-lo, tratá-lo e reabilitá-lo, entendendo o consumo de drogas como um problema de saúde pública. Desse modo, é importante trabalhar com as singularidades desse sujeito, no intuito de traçar estratégias de vida para/com o mesmo, aumentar o seu grau de liberdade e de corresponsabilidade, ou seja, fazê-lo protagonista de suas açốes ${ }^{3}$. Assim, constroem-se alternativas, tanto individuais como coletivas, de redução de danos e de riscos sociais que passam a fazer parte das políticas públicas de saúde voltadas a essa população.

A origem do modelo de reduçáo de danos se deu no Reino Unido, em 1926, e preconizava que os usuários em situação de dependência de opioides poderiam receber estas drogas sob a prescrição de um médico. Essas substâncias eram utilizadas no acompanhamento da síndrome de abstinência, em doses mínimas diárias e com fins terapêuticos, com o objetivo de minimizar sintomas danosos ao usuário, não havendo nessa conduta o fornecimento da droga com a finalidade de satisfação. A ideia de diminuir os danos em relação aos efeitos da abstinência de drogas, nessa época, foi vista como uma alternativa relevante e indispensável no cotidiano dos usuários $^{4}$. No Reino Unido, a concepção de diminuir riscos em relação ao uso de drogas se constituiu em uma prioridade adotada pelos serviços de saúde, com o propósito de redução de danos sociais e de saúde das pessoas, decorrentes do uso de substâncias psicoativas ${ }^{4}$.

Em 1984, na Holanda, as estratégias de redução de danos foram utilizadas no controle das epidemias de hepatites B e C e da AIDS. A implantaçáo dessas medidas estabeleceu-se pelos próprios usuários de drogas injetáveis, os quais perceberam que não havia açóes preventivas à contaminação de doenças transmitidas pelo compartilhamento de seringas 5 .

No Brasil, na cidade de Santos-SP, em 1989, houve as primeiras ações de redução de danos, relacionadas, também, à disseminação da AIDS. Nessa época, o país enfrentava altos índices de transmissão do vírus HIV vinculados ao uso indevido de drogas injetáveis. Começou, entáo, a primeira tentativa de reduçáo de danos com troca de seringas, por meio de uma intervenção judicial. Mais tarde, a ação foi interrompida, por ser taxada como incentivo ao uso de drogas $s^{6}$.

Nesse mesmo período, o Brasil passava por um movimento de lutas em relação ao modelo hospitalocêntrico na assistência às pessoas com transtornos mentais. Fazia-se uma crítica à violência que ocorria nos manicômios, à mercantilização da loucura, à hegemonia da rede privada de saúde e do saber psiquiátrico. Nesse mesmo ano, também na cidade de Santos, ocorreu uma importante intervenção em um hospital psiquiátrico, local de muita violência e mortes de pacientes. Essa intervenção teve repercussão nacional e colaborou para a construção de uma rede de cuidados substitutiva ao hospital psiquiátrico. Naquela época, foi implantado nesse município o Núcleo de Atenção Psicossocial (NAPS). Tal experiência passou a ser um marco no processo de reforma psiquiátrica brasileira ${ }^{7}$.

Ainda no ano de 1989, deu entrada no Congresso Nacional um projeto de lei propondo a regulamentação dos direitos da pessoa com transtornos mentais e a eliminação dos manicômios no país. Esse período marcou o início das lutas do movimento da reforma psiquiátrica nos campos legislativos e normativos no Brasil'. Aí também se iniciou, de forma clandestina, a proposta de redução de danos no país. Em 1990, a organização não governamental Instituto de Estudos e Pesquisas em AIDS de Santos (IEPAS) teve a iniciativa de distribuir seringas estéreis para os usuários de drogas injetáveis (UDIs), ensiná-los a limparem os equipamentos com hipoclorito de sódio e orientá-los a não compartilharem suas seringas ${ }^{8}$. 
Em 2006, a Lei de Drogas no 6.368/1976 foi revogada, e foi instituída a Lei $\mathrm{n}^{\circ} 11.343$, a qual preconiza que as açóes de atenção ao usuário e dependente de álcool e outras drogas e a seus familiares são aquelas que visam a melhoria da qualidade de vida desse estrato populacional, bem como a reduçáo de danos ligados ao uso de substâncias psicoativas ${ }^{9}$. Desse modo, a redução de danos, atualmente, caracteriza-se como uma estratégia de saúde que busca o tratamento das toxicomanias, a fim de oferecer aos alcoolistas e usuários de outras drogas condiçóes menos danosas à saúde, sem necessariamente interferir no consumo, visando a promoçáo da saúde, da cidadania e dos direitos humanos, descartando a lógica da abstinência e da internação como as únicas alternativas ${ }^{3}$.

Nesse cenário, é importante que o usuário de álcool e outras drogas seja visto de maneira integral, apontandose à prevenção e promoção da saúde, assim como possibilitar o acompanhamento por meio de diferentes redes e linhas de cuidados, com o objetivo de reduzir danos à sua saúde. Ressalta-se que as drogas são qualificadas em lícitas e ilícitas. As ilícitas são aquelas cujo uso é proibido pela lei. As lícitas têm o uso permitido e aceito socialmente, entretanto, possuem restriçóes legais, como a proibiçáo de venda de bebida alcoólica e tabaco para pessoas menores de $18 \operatorname{anos}^{10}$. $\mathrm{O}$ uso de drogas lícitas no Brasil, especialmente tabaco e álcool, é considerado grave problema para a saúde da populaçáo. Em relação a fatores humanos causadores de acidentes de trânsito, o álcool tem sido apontado como um dos principais. Sob a influência dessa substância, os acidentes são mais graves e o índice de mortalidade é maior ${ }^{11,12}$.

O tabaco é o agente causador de importantes problemas relacionados à saúde, além de ser um desafio no desenvolvimento econômico, social, educacional e ambiental ${ }^{13}$. No Brasil, em 2008, 17,5\% da populaçáo de 15 anos ou mais de idade era usuária de produtos derivados de tabaco, o que correspondia a 25 milhóes de pessoas. Regionalmente, o maior percentual de usuários estava no Sul (19\%), e os homens representavam o maior número de usuários ${ }^{14}$.

Em relaçáo ao uso de drogas ilícitas, a cannabis é a mais utilizada. O segundo grupo mais consumido inclui metanfetamina, anfetamina, methcathinone e ecstasy. No terceiro grupo, aparecem os opioides, derivados da papoula como ópio e heroína. A cocaína aparece em quarto lugar em termos de prevalência global ${ }^{15}$. No Brasil, o consumo de crack tornou-se, hoje, um importante fenômeno de saúde pública ${ }^{16,17}$, devido às graves consequências que o uso dessa substância acarreta. Um estudo com 332 usuários de cocaína da cidade de São Paulo-SP encontrou que $50 \%$ deles apresentavam alguma complicação, com $84 \%$ relatando calor e rubor, $76 \%$, tremores incontroláveis, $21 \%$, desmaios, e $18 \%$, convulsōes ${ }^{18}$.
Outra pesquisa realizada com usuário de crack, nessa mesma cidade, no período de um ano, apontou três fatores de riscos em relação ao uso dessa substância: riscos decorrentes da ilegalidade da droga e da vivência do tráfico, relacionados à violência originada tanto do grupo de traficantes quanto da polícia; efeitos psíquicos da droga, associados especialmente aos quadros de fissura e paranóia, as quais estão diretamente coligadas a lesões físicas devido a brigas, comportamento sexual arriscado, detenção policial e perda de vínculos; e, por último, riscos advindos de complicaçóes físicas decorrentes do uso da droga, como overdose, emagrecimento e insônia ${ }^{19}$.

Devido a esses fatores relacionados ao abuso de drogas e, consequentemente, da dimensão que essa situação alcançou, a política de redução de danos vem se inserindo como um desafio em nível mundial, enfrentando obstáculos legais, políticos, éticos e sociais, ampliandose nos mais diversos espaços e serviços de saúde ${ }^{10}$. No Brasil, o Consultório na Rua constitui-se em um dos resultados dessa política. Pesquisa com profissionais que desenvolveram atividades no Consultório na Rua mostrou intervençóes importantes nesse espaço, principalmente a construção de vínculo, que se constituiu na base para o sucesso do trabalho de redução de danos, pois este possibilitou, acima de tudo, a aceitação e empatia do usuário de álcool e outras drogas ${ }^{20}$.

O Programa de Redução de Danos de Porto AlegreRS realizou parceria com unidades de saúde, disponibilizando kits de material para a utilização de drogas injetáveis, assim como o trabalho de prevenção e assistência junto aos UDIs ${ }^{10}$. Usuários de uma Unidade de Redução de Danos avaliaram positivamente as açóes desenvolvidas pela equipe, com enfoque no acolhimento, na distribuição de insumos e nas práticas educativas ligadas a doenças sexualmente transmissíveis e ao não compartilhamento de canudos e de cédulas de dinheiro para o uso de drogas, devido ao risco de contaminação21. Estudo realizado com 10 usuários de crack em tratamento em um Centro de Atenção Psicossocial Álcool e Drogas (CAPSad) e em um Centro de Atenção Psicossocial Infantil (CAPSi) assinalou que alguns toxicômanos usam a maconha como um auxílio na diminuição da fissura pelo crack, concluindo que o uso da maconha pode se enquadrar como uma estratégia de redução de danos ${ }^{22}$.

Devido à gravidade dos riscos, tanto pessoais como sociais, decorrentes do uso de drogas lícitas e ilícitas e à proporção que seu uso alcançou nos últimos anos no país, com destaque para o álcool e tabaco, constatou-se a necessidade e a importância de buscar, na literatura nacional, o que tem sido publicado sobre as políticas de redução de danos implantadas no Brasil e a maneira como estas vêm sendo trabalhadas, no decorrer dos anos de 2006 até 2012. A escolha pelo período justifica-se 
pelo fato da implantação da Lei no $11.343 / 2006$, de redução de danos 9 . Ainda, pelo fato de que a política de redução de danos é relativamente recente, sendo importante conhecer as produçóes científicas publicadas em relação a essa temática e analisar sua aplicabilidade junto à população usuária de álcool e outras drogas. Além disso, a partir dessa revisão, pode-se estimular a produção de novos estudos com enfoque nesse assunto, com vistas a fortalecer as discussóes nesse campo do saber.

Assim, este estudo objetiva analisar artigos publicados on-line em periódicos nacionais, no período de 2006 a 2012, relativos às políticas de redução de danos implantadas no Brasil.

\section{Método}

Trata-se de uma revisão narrativa de literatura. A busca bibliográfica foi desenvolvida na Biblioteca Virtual de Saúde, em periódicos nacionais, disponíveis nas bases de dados: Literatura Latino-Americana e do Caribe em Ciências da Saúde, Base de Dados de Enfermagem e Coleção Scientific Eletronic Library Online. A busca ocorreu em abril de 2013, com a utilização da palavrachave "reduçáo de danos" e do descritor "reduçáo do dano".

A delimitação temporal foi o período entre os anos de 2006 a 2012, com ponto inicial no ano em que foi decretada a Lei $\mathrm{n}^{\circ} 11.343$, que visa a melhoria da qualidade de vida e a redução dos riscos e dos danos associados ao uso de drogas no Brasil9. Foram incluídos na pesquisa artigos originais com disponibilidade do texto completo em suporte eletrônico, do foco de interesse, publicados em periódicos nacionais. Os critérios de exclusão foram artigos de revisão bibliográfica, artigos de reflexão, relatos de experiência, artigos internacionais, artigos que se repetiram em termos de conteúdos nas diferentes bases de dados, guias, pesquisa documental, teses e editoriais.

Com a utilização do descritor "redução do dano", na base de dadoLilacs, emergiram 58 publicaçóes; na BDENF, 4; e, na Scielo, 8. Quando utilizada a palavrachave "redução de danos", não foi localizada nenhuma publicação no LILACS; na BDENF, foram localizadas 14; e, na Scielo, foram encontradas 13 publicaçóes. Portanto, foram localizadas 97 publicaçóes ao todo.

Das 97 publicaçóes, 58 estavam inclusas no recorte temporal. Das 58 selecionadas, 9 foram excluídas por serem teses, 10 por serem internacionais, 4 por serem relatos de experiência, 6 por serem artigos de reflexão, 8 por serem revisão bibliográfica, 2 por serem pesquisas documentais, 2 por serem guias, 1 por ser texto-debate, 2 por serem editoriais. Desse modo, restaram 14 artigos originais; entretanto, 1 deles foi excluído por estar fora da temática proposta e 4 por se repetirem nas bases de dados. Assim sendo, 9 publicaçóes compóem o presente estudo.

O material bibliográfico foi submetido à técnica de análise de conteúdo temática ${ }^{23}$, a qual consta de três etapas: pré-análise, exploraçáo do material e interpretação dos resultados. A primeira etapa possibilitou visão geral do conteúdo dos artigos, por meio da leitura dos resumos e fichamento. Os textos na íntegra, após uma primeira leitura, foram organizados com o auxílio de um formulário composto das variáveis: ano/autor, objetivos, tipo de estudo, local e resultados encontrados. A etapa de exploração do material foi desenvolvida a partir da releitura dos textos, culminando na construção de categorias temáticas de análise. Posteriormente, na etapa de interpretação dos resultados, foram observadas as colocaçóes existentes sob a ótica de diferentes autores.

\section{Resultados e discussões}

A partir da leitura dos artigos, considerando a similaridade das informaçôes, emergiram dois temas. O primeiro versa sobre a organização e implantação de açóes de redução de danos no Brasil, e o segundo aborda a construção da política de redução de danos na sociedade contemporânea como um novo saber. O Quadro 1 mostra os artigos analisados.

A partir da análise sobre a publicação nacional envolvendo a temática acerca do álcool e outras drogas e a política de redução de danos, verifica-se que os estudos, em sua maior parte, são descritivos e utilizam a abordagem qualitativa e quantitativa. Há predomínio de profissionais compondo a amostra dos participantes, seguidos de pessoas usuárias e dependentes de substâncias psicoativas. No período estudado, identifica-se superioridade de pesquisas realizadas nas regióes Sul e Sudeste do Brasil. Em relação aos autores, observa-se que, em alguns artigos, não há a identificação da categoria profissional dos autores. Naqueles que identificam os autores, a maior parte destes está vinculada à docência. Ainda, vale ressaltar que parte significativa da produção bibliográfica nessa área do conhecimento é realizada por profissionais enfermeiros e psicólogos.

\section{Organização e Implantação das Práticas de Redução de Danos no Brasil}

Em relação à organização e implantação das práticas de reduçâo de danos, dois artigos (A1 e A3) apontam as fragilidades das equipes de saúde, referentes à falta de supervisão e de coordenaçáo dos serviços em campo. Um dos estudos (A3) evidencia a independência e 
Quadro 1: Classificação dos artigos selecionados segundo autor, ano de publicação, objetivos, tipo de estudo, local do estudo e resultados.

\begin{tabular}{|c|c|c|c|c|c|}
\hline $\begin{array}{c}\text { Identificaçáo } \\
\text { do artigo }\end{array}$ & Autor/ano & Objetivos & $\begin{array}{l}\text { Tipo de } \\
\text { estudo }\end{array}$ & Local & Resultados \\
\hline A1 & $\begin{array}{c}\text { Nardi e } \\
\text { Rigoni/2009 }\end{array}$ & $\begin{array}{l}\text { Descrever a forma de } \\
\text { funcionamento das } \\
\text { ações e programas } \\
\text { de redução de danos } \\
\text { desenvolvidos nos } \\
\text { municípios da região } \\
\text { metropolitana de } \\
\text { Porto Alegre }\end{array}$ & $\begin{array}{c}\text { Não } \\
\text { especificado }\end{array}$ & $\begin{array}{l}\text { Região me- } \\
\text { tropolitana de } \\
\text { Porto Alegre }\end{array}$ & $\begin{array}{l}\text { Apesar da diversidade de vínculos e formas } \\
\text { de organizaçáo dos locais analisados, } \\
\text { algumas características são comuns, como: } \\
\text { inserção profissional precária; dependência } \\
\text { do trabalho voluntário para a execuçáo } \\
\text { das atividades; influência das mudanças de } \\
\text { gestão municipal e estadual para a continui- } \\
\text { dade de projetos e de parcerias, assim como } \\
\text { para a manutençáo de recursos humanos e } \\
\text { financeiros dos programa }\end{array}$ \\
\hline $\mathrm{A} 2$ & $\begin{array}{l}\text { Landi Filho, } \\
\text { Araújo, } \\
\text { Oliveira, } \\
\text { Cavalcante } \\
\text { e Miranda } \\
\text { Junior/2009 }\end{array}$ & $\begin{array}{c}\text { Avaliar o grau de } \\
\text { conhecimento dos } \\
\text { profissionais do } \\
\text { Programa Saúde da } \\
\text { Família quanto às } \\
\text { ações de redução de } \\
\text { danos em grupos de } \\
\text { risco }\end{array}$ & $\begin{array}{l}\text { Estudo } \\
\text { transversal, } \\
\text { descritivo e } \\
\text { observacio- } \\
\quad \text { nal }\end{array}$ & $\begin{array}{l}\text { Três regiōes } \\
\text { administrati- } \\
\text { vas de saúde } \\
\text { do Distrito } \\
\text { Federal: Gama, } \\
\text { Recanto das } \\
\text { Emas e Guará. }\end{array}$ & $\begin{array}{l}\text { Destaca-se que a maioria dos entrevistados } \\
(77,6 \%) \text { desconhecem o PRD; mais de } 65 \% \\
\text { nunca tiveram contato com os redutores de } \\
\text { danos e mais de dois terços não procuram } \\
\text { informaçóes sobre esta estratégia }\end{array}$ \\
\hline A3 & $\begin{array}{l}\text { Souza, Kantorski, } \\
\text { Gonçalves, } \\
\text { Mielke e } \\
\text { Guadalupe/2007 }\end{array}$ & $\begin{array}{l}\text { Analisar o funcio- } \\
\text { namento de um } \\
\text { Centro de Atenção } \\
\text { Psicossocial Álcool e } \\
\text { Drogas como novo } \\
\text { modelo de assistên- } \\
\text { cia e sua interação } \\
\text { com o Serviço de } \\
\text { Reduçáo de Danos }\end{array}$ & $\begin{array}{l}\text { Estudo } \\
\text { qualitativo } \\
\text { do tipo } \\
\text { descritivo }\end{array}$ & $\begin{array}{l}\text { Município da } \\
\text { região sul do } \\
\text { Rio Grande } \\
\quad \text { do Sul }\end{array}$ & $\begin{array}{l}\text { Aponta-se uma rede de serviços relati- } \\
\text { vamente desconexa, porém com vastas } \\
\text { possibilidades para complementaridade da } \\
\text { atenção; observou-se a influência da for- } \\
\text { maçáo médica hospitalocêntrica e a falta de } \\
\text { engajamento de alguns profissionais como } \\
\text { fatores importantes no conjunto de desafios } \\
\text { para a consolidação de uma nova proposta } \\
\text { de assistência }\end{array}$ \\
\hline A4 & $\begin{array}{c}\text { Salmeron } \\
\text { e Martins } \\
\text { Pessoa/2012 }\end{array}$ & $\begin{array}{c}\text { Identificar o perfil } \\
\text { socioepidemiológico } \\
\text { de profissionais do } \\
\text { sexo e estabelecer } \\
\text { medidas de redução } \\
\text { de danos }\end{array}$ & $\begin{array}{l}\text { Estudo } \\
\text { descritivo, } \\
\text { explorató- } \\
\text { rio, com } \\
\text { abordagem } \\
\text { quantitativa. }\end{array}$ & $\begin{array}{l}\text { Cinco casas } \\
\text { noturnas situa- } \\
\text { das na Zona } \\
\text { Sul da cidade } \\
\text { de São Paulo }\end{array}$ & $\begin{array}{c}\text { A idade variou entre } 21 \text { e } 41 \text { anos entre os } \\
\text { sujeitos, que recebiam entre R\$1001,00 } \\
\text { e R\$3000,00. Quanto aos antecedentes } \\
\text { pessoais, 54\% já provocaram aborto e } \\
\text { faziam, em média, } 15 \text { programas semanais; } \\
\text { observou-se que } 68 \% \text { utilizavam algum } \\
\text { tipo de droga e } 86 \% \text { já usaram pílula do dia } \\
\text { seguinte }\end{array}$ \\
\hline A5 & $\begin{array}{c}\text { Souza e } \\
\text { Monteiro/2011 }\end{array}$ & $\begin{array}{c}\text { Contribuir para o } \\
\text { desenvolvimento } \\
\text { e avaliação de pro- } \\
\text { gramas educativos } \\
\text { sobre saúde, drogas e } \\
\text { temas afins }\end{array}$ & $\begin{array}{c}\text { Abordagem } \\
\text { qualitativa }\end{array}$ & $\begin{array}{l}\text { Cinco orga- } \\
\text { nizaçóes não } \\
\text { governamentais } \\
\text { de educação } \\
\text { não formal de } \\
\text { adolescentes } \\
\text { e jovens no } \\
\text { estado do Rio } \\
\text { de Janeiro }\end{array}$ & $\begin{array}{l}\text { Houve apropriação e ressignificação, pelos } \\
\text { educadores, dos conceitos abordados no } \\
\text { projeto relativos a educaçáo para autono- } \\
\text { mia, redução de danos e vulnerabilidade, } \\
\text { orientados por uma abordagem dialógica } \\
\text { e crítica do processo de construção do } \\
\text { conhecimento }\end{array}$ \\
\hline
\end{tabular}


Quadro 1: Continuação

\begin{tabular}{|c|c|c|c|c|c|}
\hline $\begin{array}{c}\text { Identificaçáo } \\
\text { do artigo }\end{array}$ & Autor/ano & Objetivos & $\begin{array}{l}\text { Tipo de } \\
\text { estudo }\end{array}$ & Local & Resultados \\
\hline A6 & $\begin{array}{c}\text { Delbon, Da Ros e } \\
\text { Ferreira/2006 }\end{array}$ & $\begin{array}{c}\text { Sensibilizar os } \\
\text { profissionais para } \\
\text { o acolhimento e } \\
\text { disponibilização dos } \\
\text { insumos de redução } \\
\text { de danos }\end{array}$ & $\begin{array}{l}\text { Metodologia } \\
\text { quantitativa } \\
\text { e qualitativa }\end{array}$ & $\begin{array}{c}\text { São Paulo, } \\
\text { durante o } \\
\text { período de } \\
\text { julho de } 2003 \\
\text { a novembro de } \\
2004\end{array}$ & $\begin{array}{l}\text { A introdução do conceito de redução de } \\
\text { danos nos CAPSad fez que se compreen- } \\
\text { desse a complexidade da tarefa e o impacto } \\
\text { no serviço e no território de abrangência. } \\
\text { Desenharam-se treinamentos e reuniōes de } \\
\text { fortalecimento para sensibilização da equipe } \\
\text { de saúde, usuários de drogas, familiares e } \\
\text { comunidade. Porém, açâo de distribuição } \\
\text { de kits desperta polêmica na comunidade } \\
\text { e medo e preconceito nos profissionais por } \\
\text { lidar com drogas ilícitas - algo proibido -, } \\
\text { os quais temem ser cúmplices, ao invés de } \\
\text { curar o dependente }\end{array}$ \\
\hline A7 & $\begin{array}{c}\text { Jahn, Rossato, } \\
\text { Oliveira e } \\
\text { Melo/2007 }\end{array}$ & $\begin{array}{l}\text { Conhecer a história } \\
\text { de pessoas alcoolis- } \\
\text { tas que frequentam } \\
\text { grupos de ajuda do } \\
\text { CAPSad }\end{array}$ & $\begin{array}{c}\text { Estudo de } \\
\text { abordagem } \\
\text { qualitativa } \\
\text { do tipo } \\
\text { descritivo } \\
\text { exploratório. }\end{array}$ & $\begin{array}{l}\text { CAPSad do } \\
\text { município de } \\
\text { Santa Maria } \\
\text { (RS), no ano } \\
2005\end{array}$ & $\begin{array}{l}\text { Os resultados evidenciaram que os grupos } \\
\text { de ajuda são vistos pelos alcoolistas como } \\
\text { uma família, uma casa, um lugar seguro, } \\
\text { onde todos convivem com o mesmo proble- } \\
\text { ma, ajudam-se mutuamente para consegui- } \\
\text { rem se manter em abstinência e adquirirem } \\
\text { força para reconstruir suas famílias e recupe- } \\
\text { rarem a confiança e a dignidade, que ficam } \\
\text { comprometidas pelo processo da doença }\end{array}$ \\
\hline A8 & $\begin{array}{c}\text { Schlichtin, Boog e } \\
\text { Campos/2007 }\end{array}$ & $\begin{array}{l}\text { Estudar e discutir a } \\
\text { experiência do almo- } \\
\text { ço como momento } \\
\text { terapêutico, explici- } \\
\text { tando pressupostos } \\
\text { teóricos, estratégias e } \\
\text { resultados imediatos }\end{array}$ & $\begin{array}{l}\text { Utilizou-se } \\
\text { método } \\
\text { clínico } \\
\text { qualitativo }\end{array}$ & $\begin{array}{c}\text { CRIAD no } \\
\text { município de } \\
\text { Campinas (SP) }\end{array}$ & $\begin{array}{l}\text { Percebe-se a valorizaçáo do ambiente pelo } \\
\text { fato da substituiçáo de utensílios descar- } \\
\text { táveis pelos de uso permanente, o que } \\
\text { contribui para a melhoria da autoestima. O } \\
\text { almoço proporciona um espaço de reflexáo, } \\
\text { explicitando dúvidas, dificuldades, insegu- } \\
\text { ranças e preconceitos; as mulheres puderam } \\
\text { compartilhar seus sentimentos e se sentirem } \\
\text { mutuamente amparadas. O alimento pode } \\
\text { ser considerado uma estratégia de RD, } \\
\text { uma vez que, ao se alimentar, o dependen- } \\
\text { te químico minimiza os danos físicos da } \\
\text { substância no organismo. A intervençáo de } \\
\text { educação em nutrição passa pelos compo- } \\
\text { nentes subjetivos da alimentaçáo e pelos } \\
\text { relacionamentos que se dão em torno dela }\end{array}$ \\
\hline A9 & $\begin{array}{l}\text { Botti, Lima e } \\
\text { Simóes/2010 }\end{array}$ & $\begin{array}{l}\text { Identificar o padrão } \\
\text { do consumo de subs- } \\
\text { tâncias psicoativas } \\
\text { entre estudantes do } \\
\text { curso de enfermagem }\end{array}$ & $\begin{array}{c}\text { Estudo } \\
\text { descritivo } \\
\text { transver- } \\
\text { sal com } \\
\text { abordagem } \\
\text { quantitativa }\end{array}$ & Betim (MG) & $\begin{array}{l}\text { Os dados mostram o predomínio do "uso na } \\
\text { vida" de substâncias psicoativas lícitas como } \\
\text { a bebida alcoólica ( } 89,57 \%) \text { e o tabaco } \\
\text { ( } 31,30 \%) \text {. Em relação às ilícitas, houve } \\
\text { prevalência do uso de ansiolíticos (19,08\%), } \\
\text { seguidos dos inalantes ( } 15,52 \%) \text {, anorexí- } \\
\text { genos ( } 13,99 \%) \text { e maconha ( } 12,72 \%) \text {, } \\
\text { enquanto a cocaína correspondeu a } 2,29 \% \text {. } \\
\text { O uso de substâncias psicoativas pelos estu- } \\
\text { dantes é expressivo, tornando-se um fator } \\
\text { preocupante no que diz respeito à saúde } \\
\text { dessa população }\end{array}$ \\
\hline
\end{tabular}


a maneira desconexa como os profissionais redutores de danos trabalham em relação a um serviço substitutivo da área da saúde mental, ou seja, um CAPSad. O outro (A1), no entanto, mostra as dificuldades em formar uma equipe coesa, integrada e comprometida com os objetivos do programa de reduçáo de danos, devido às especificidades do perfil dos redutores. Ainda, outro estudo analisado (A6) coloca que os redutores de danos apresentam problemas de adaptação às normas de trabalho vinculadas à área da saúde, em função de serem pessoas provindas de suas próprias comunidades, quase sempre sem formação profissional especializada.

A Política Nacional de Humanização (PNH) do Ministério da Saúde se posiciona de maneira contrária à supervisão única e centralizada dos serviços de saúde. A mesma propóe a participação coletiva como modelo de gestão, em que os sujeitos são protagonistas no processo de produção de saúde. A cogestão é construída coletivamente e garante o poder compartilhado nas açóes e decisóes em relação ao processo saúde-doença ${ }^{24}$. O compromisso de maneira coletiva, dentro dos grupos de trabalho, permite autonomia e, principalmente o, empoderamento dos sujeitos prestadores de serviço, o que contribui para a responsabilização social com os usuários. Uma experiência de ensino e aprendizagem positiva dos redutores de danos a usuários e não usuários ocorre por meio de cursos de formaçáo, congressos, conferências e encontros em que estes participam de forma ativa. A vivência mostra que os redutores de danos tornam-se exemplos a serem seguidos pelos demais usuários na comunidade e integram-se de maneira satisfatória à equipe de trabalho ${ }^{25}$. Quando o redutor de danos participa de uma formação continuada, além de reconhecer sua importância como cidadão, prepara-se para as atividades diárias de campo, integrando-se, consequentemente, à equipe e ao seu processo de trabalho, de forma conexa.

Contudo, a prática de reduzir danos ao usuário de álcool e outras drogas deve envolver todos os atores, usuários, profissionais e comunidade em geral. Nota-se, em um artigo analisado (A1), que as açôes de redução de danos eram executadas por uma organização não governamental $(\mathrm{ONG})$ em um município, por meio de trabalhos voluntários e por agentes comunitários de saúde (ACSs). As ONGs, nas açóes de redução de danos, fazem parte da rede de suporte social e de apoio comunitário, pelo trabalho voluntário. Entretanto, essa não deve ser a única forma de trabalho articulado. $\mathrm{O}$ objetivo não é centralizar a assistência, e sim trabalhar com redes e linhas de cuidado, incluindo CAPS, Unidades Básicas de Saúde, Unidades com Estratégia de Saúde da Família, comunidade,entre outros.

O CAPS tem importante papel por ser um serviço vinculado ao campo da saúde mental. Ele tem a responsabilidade de organizar a rede de serviços de saúde mental de seu território, necessitando articular-se permanentemente com outras redes sociais ${ }^{26}$. Quatro trabalhos avaliados no estudo (A1, A3, A6 e A7) mencionam que o CAPS é uma ferramenta na construçáo da inclusão social do usuário de álcool e outras drogas, com destaque para a política de redução de danos. O programa de redução de danos se constitui em um dos eixos que integra a rede de atençáo integral à saúde mental, com o objetivo de oferecer açóes de promoçáo, prevenção e cuidados primários no espaço da rua ${ }^{27}$.

Dois artigos em análise (A1 e A5) pontuam a falta de apoio financeiro como impasse nas açóes do programa de redução de danos. Observa-se, também, a dificuldade em sensibilizar os gestores da importância dessas ações junto aos usuários de drogas psicoativas. Isso se deve, normalmente, a que seus resultados são pouco visíveis.

O enfrentamento ao uso de drogas, a partir das políticas recentes implantadas nacionalmente, objetivam ultrapassar antigos paradigmas. Entretanto, existem ainda resistências a essas novas formas de se trabalhar com o usuário de drogas, por parte dos gestores do Sistema Único de Saúde (SUS), profissionais e comunidade. O preconceito com usuários de drogas é comum na sociedade. A ideia é que esses sujeitos sáo inteiramente culpados pela sua atual situação, o que contribui para sua exclusão social.

Existem vários motivos que levam ao uso de substâncias psicoativas, entre elas: influência de pessoas próximas, atividades festivas, busca pelo prazer, problemas conjugais, depressão, desestruturação familiar, violência doméstica, estresse, cobranças, codependência e gravidez na adolescência ${ }^{28}$. Ainda, a drogadição na adolescência pode ser entendida como uma expressão da linguagem no adolescer, sendo esta uma das maneiras encontradas pelos jovens de socializar-se ${ }^{29}$. Nessa perspectiva, é necessário compreender o uso de drogas e os reais objetivos da política de redução de danos pelos profissionais envolvidos, a fim de evitar condutas moralistas no ambiente de trabalho e estigmas referentes à sua implantação.

Alguns profissionais da área da saúde desconhecem a política de redução de danos como uma possibilidade de intervenção e reforça que a meta ideal é a abstinência. No entanto, a proposta de redução de danos não é oposta à abstinência; ela pode ser uma alternativa de reduzir prejuízos para algumas pessoas, mas é importante que essa conclusão seja do próprio usuário, junto com a equipe, e não algo imposto num projeto terapêutico ${ }^{30}$. Observa-se que é significativa a discussão sobre a política de redução de dano, com a intenção de evitar divergência nas falas da equipe. Esta deve preocupar-se com melhores condiçóes de vida dos usuários e compreender que a abstinência é uma escolha destes. 
A redução de danos está inserida como uma estratégia de saúde que visa o tratamento das toxicomanias, a fim de oferecer aos alcoolistas e usuários de outras drogas, condiçôes menos danosas à saúde, sem necessariamente interferir no consumo, visando a promoção da saúde, cidadania e direitos humanos, descartando a lógica exclusiva da abstinência e da internaçãa ${ }^{31}$.

Identifica-se em dois estudos analisados (A5 e A6) que o trabalho com redução de danos é um fator polêmico em relação à sociedade e aos profissionais de saúde. Um dos artigos fala sobre a dificuldade da comunidade em aceitar a intervenção de redução de danos; esta afirma que, em sua regiẫo, não há usuários de substâncias psicoativas e que, se estão ali, é devido à disponibilidade dos kits de reduçáo de danos, os quais são compostos por seringas, agulhas, swabs, preservativos, água destilada, copo plástico e material informativo. Observa-se também o medo e o preconceito dos profissionais da área da saúde frente à temática.

Estudos mostram que o programa de troca de seringas é utilizado mundialmente e se mostra como um instrumento eficaz. A substituiçáo de seringas usadas por novas diminui a expansão de epidemias como a AIDS entre os usuários de drogas injetáveis, além de prevenir outras enfermidades ${ }^{32,33}$. Três estudos analisados (A1, A3 e A6) colocam a distribuição de kits como importante estratégia de redução de danos. Há necessidade de discutir essa forma de intervenção nas equipes de saúde e mostrar o respaldo legal que os profissionais possuem. Além disso, é necessário entender o usuário de substâncias psicoativas como um doente, que precisa de tratamento. Nesse sentido, estudos assinalam que os profissionais enfermeiros atuantes em um CAPSad compreendem o usuário de álcool e outras drogas como um indivíduo que precisa de tratamento. Para tanto, as equipes de saúde devem trabalhar no sentido da promoção da saúde e pensar em educação permanente em saúde, no intuito de avançar conhecimentos e ultrapassar o modelo tradicional de saúde mental ${ }^{34,35}$.

A atuação da equipe de saúde mental nos serviços substitutivos tem sido marcada por avanços na construção do modelo de atenção psicossocial. Contudo, o comprometimento dos profissionais de saúde mental com os usuários, em seu ambiente de trabalho, não deve ser assumido de maneira isolada, caso contrário, pode gerar sofrimento no profissional. A responsabilidade pelos sucessos e fracassos e pelo modo de vida do usuário em seu território, deve ser compartilhada por toda a equipe $^{35}$. Contudo, estudo evidenciou que os profissionais vinculados a um CAPSad avaliam com êxito suas tarefas junto a dependentes de substâncias psicoativas, em que há confiança, valorização e responsabilidade, por estarem produzindo atenção psicossocial, independentemente das tensôes do cotidiano ${ }^{36}$.
Para que se possa organizar e implantar as políticas de redução de danos, é necessário discutir teoricamente a reforma psiquiátrica e aplicar tais conhecimentos nas práticas dos serviços de saúde. É preciso inserir profissionais, gestores e comunidade nas discussóes sobre as novas propostas de trabalho. É importante respeitar a autonomia do usuário de modo que ele seja corresponsável pelo sucesso ou fracasso do seu projeto terapêutico.

\section{A Construção da Política de Redução de Da- nos na Sociedade como um Novo Saber}

Três estudos (A4, A5 e A9) abordam a dimensão das discussões relacionadas à política de redução de danos nos últimos anos, pontuando a necessidade de minimizar prejuízos referentes ao uso de drogas lícitas e ilícitas junto a novos atores expostos a esse risco. $\mathrm{O}$ artigo $\mathrm{A} 4$ salienta a necessidade de reduzir danos em profissionais do sexo, em casas de prostituição. Os estudos A5 e A9 falam da necessidade da implantação de políticas preventivas de redução de danos em escolas e universidades.

As políticas de redução de danos ampliaram-se, tornando-se objeto de vários campos do saber, com uma abordagem de cunho social, que envolve ética, direitos humanos, proibicionismo, doenças transmissíveis, entre outros temas. A redução de danos permeia, além das abordagens individuais, as coletivas que envolvem a sociedade nas questóes relacionadas ao uso de drogas ${ }^{37}$.

Nessa perspectiva, sete artigos (A1, A2, A3, A4, A5, A6 e A8) trabalham com a proposta de conscientização/ educação como estratégia de redução de danos. A partir de estudo realizado em um CAPSad, foi possível identificar que um grupo terapêutico de educação em saúde proporcionou reflexão sobre os danos físicos, mentais, sociais e afetivos ocasionados pelo consumo de substâncias psicoativas, fazendo que o usuário identificasse suas próprias condutas, considerasse os prejuízos, as perdas e elaborasse alternativas de mudanças relacionadas aos comportamentos comprometidos com o autocuidado ${ }^{38}$. Nesse contexto, o grupo de educação em saúde contribui para o sujeito na construção da autonomia e corresponsabilização por seu processo de cuidar. Os grupos são influências positivas na construção do saber coletivo, são espaços de discussão em que os usuários identificam suas demandas terapêuticas e se envolvem no cuidado ampliado em saúde ${ }^{39}$. Nesse mesmo sentido, os estudos A3, A6, A7 e A8 mencionam que os espaços de grupos são estratégias de redução de danos. Dois destes descrevem a mútua ajuda como um fator importante, uma vez que seus participantes vivenciam os mesmos problemas, auxiliam-se compartilhando suas experiências, 
o que lhes dá suporte para enfrentar o cotidiano social e familiar sem o uso de substâncias psicoativas.

As relaçóes de grupo de apoio oferecem suporte aos participantes, constituindo-se em recursos terapêuticos. O compartilhamento de experiências com outras pessoas em situaçóes similares possibilita a mútua ajuda e a melhoria da qualidade de vida de seus integrantes ${ }^{39,40}$. Nessa lógica, os grupos se inserem de maneira significativa como práticas de reduçáo de danos, tornando-se importantes ferramentas de cuidado, e se apresentam como fonte de escuta, de construção coletiva de inclusão social e de valores pessoais.

Em um dos estudos analisados (A8), o alimentar-se coletivamente é uma estratégia relevante de redução de danos, em que a refeição se constitui em um momento de compartilhamento, troca de afetos e de diálogo. $\mathrm{O}$ ato de comer é construído socialmente e deve ser visto e entendido a partir dos vários olhares das áreas do saber: biológico, antropológico, sociológico e psicológico. $\mathrm{O}$ alimentar-se coletivo proporciona às pessoas uma ocasião de encontro informal e involuntário com caráter terapêutico, que traz benefícios para os envolvidos, formando um grupo coeso de discussão de diferentes temáticas ${ }^{41}$.

Em relação à redução de danos, constata-se avanço no processo de cuidado, individual e coletivo. A política contempla a participação de outros sujeitos. Em vez de ser direcionada apenas aos profissionais da área da saúde, envolve família, vizinhos, igreja, ONGs, voluntários, gestores, usuários em recuperação e comunidade em geral. Desse modo, é possível construir uma linha de cuidados ampliada, buscando a melhor forma de reduzir danos à saúde e incluir os sujeitos dependentes de substâncias psicoativas na sociedade.

\section{Considerações finais}

A literatura nacional sobre álcool e outras drogas e sobre a política de redução de danos evidencia que, desde a implantação desta, tanto as equipes de saúde como gestores municipais e sociedade vêm encontrando dificuldades de articulaçáo e integração, tendo limitaçóes para efetivação da política. Há precariedade no financiamento relacionado a ela, que, na maioria das vezes, focaliza o trabalho em instituiçóes de cunho voluntário.

Por vezes, as açóes de redução de danos estão centralizadas nos redutores de danos, as quais podem mostrar-se frágeis e pouco eficazes. Isso se deve, em muitas situaçóes, à falta de preparo desses profissionais para o desempenho de tais atividades. Assim, é necessário promover espaços de discussão acerca dos pressupostos teóricos da reforma psiquiátrica e das políticas de redução de danos, em associação com o fazer da prática cotidiana. Cabe, ainda, destacar que atividades de redução de danos devem ser realizadas por toda a equipe de saúde, nas quais o próprio sujeito dependente de substâncias psicoativas seja protagonista e corresponsável pela construção/reconstrução de sua vida e de seus valores.

A educação permanente direcionada ao campo da política de redução de danos se constitui em uma estratégia de cuidado de saúde mental. É necessário haver intersetorialidade e implicação das equipes de saúde ao articular novos saberes e novas propostas a esse projeto de vida, que é a política de redução de danos para usuários de álcool e outras drogas no Brasil.

\section{Referências}

1. Escohotado A. Las drogas: de losorígenes a laprohibición [Internet]. Madrid: Alianza; 1994 [acesso em 2013 Abr 14]. Disponível em:http://pt.scribd.com/doc/40114500/ Escohotado-Las-drogas-de-los-origenes-a-la-prohibicion

2. Macrae E. Aspectos socioculturais do uso de drogas e políticas de redução de danos[Internet]. s/d [acesso em $11 \mathrm{Dez}$ 2013]. Disponível em: http://www.neip.info/index.php/ content/view/2469.htm

3. Brasil, Ministério da Saúde, Secretaria de Atenção à Saúde. SVS/CN-DST/AIDS. A política do Ministério da Saúde para atenção integral a usuários de álcool e outras drogas/Ministério da Saúde.2a ed. Brasília: Ministério da Saúde; 2004.

4. Oliveira MGPN. Consultório de rua: relato de uma experiência [dissertação]. Salvador: Universidade Federal da Bahia; 2009.

5. Fernandes L, Ribeiro C. Redução de riscos, estilos de vida junkie e controlo social. Sociologia. 2002 Ago;39:57-68.

6. Mesquita F, Bueno R, Kral A, Reingold A, Lopes G, Haddad I, et al. AIDS entre usuários de drogas injetáveis na região metropolitana de Santos, na década de 1990. In: Brasil, Ministério da Saúde, Secretaria Executiva, Coordenação Nacional de DST e AIDS. A contribuição dos estudos multicêntricos frente à epidemia de HIV/AIDS entre UDIs no Brasil: 10 anos de pesquisa e redução de danos. Brasília: Ministério da Saúde; 2001.

7. Brasil, Ministério da Saúde, Secretaria de Atenção à Saúde, DAPE, Coordenação Geral de Saúde Mental. Reforma psiquiátrica e política de saúde mental no Brasil. Documento apresentado à Conferência Regional de Reforma dos Serviços de Saúde Mental: 15 anos depois de Caracas. OPAS. Brasília: Ministério da Saúde; 2005.

8. Trigueiros DT, Haiek RC. Estratégias de redução de danos entre usuários de drogas injetáveis. In: Silveira D, Moreira FG. Panorama atual de drogas e dependência. São Paulo: Atheneu; 2006.

9. Brasil. Lei $n^{\circ} 11.343$, de 23 de agosto de 2006. Institui o Sistema Nacional de Políticas Públicas sobre Drogas 
- Sisnad; prescreve medidas para prevenção do uso indevido, atenção e reinserção social de usuários e dependentes de drogas; estabelece normas para repressão à produção não autorizada e ao tráfico ilícito de drogas; define crimes e dá outras providências. Presidência da República, Casa Civil, Subchefia para Assuntos Jurídicos.

10. Fonseca E, Bastos FI. Políticas de reduçấo de danos em perspectiva: comparando as experiências americana, britânica e brasileira. In: Acselrad G. Avessos do prazer: drogas, AIDS edireitos humanos. $2^{\mathrm{a}}$ ed. Rio de Janeiro: Fiocruz; 2005.

11. Abreu AMM, Lima JMB, Matos LN, Pilon SC. Uso de álcool em vítimas de acidentes de trânsito: estudo do nível de alcoolemia. Rev Latino-Am Enfermagem. 2010 Mai/ Jun;8(n. especial):513-20.

12. Modelli MES, Pratesi R, Tauil PL. Alcoolemia em vítimas fatais de acidentes de trânsito no Distrito Federal, Brasil. Rev Saúde Pública. 2008. Fev;42(2):350-2.

13. Machado VC, Alerico MI, Sena J. Programa de prevençẫo e tratamento do tabagismo: uma vivência acadêmica de enfermagem. Cogitare Enferm. 2007 Abr/Jun;12(2):248-52.

14. Brasil, Ministério da Saúde, Instituto Nacional do Câncer, Instituto Brasileiro de Geografia e Estatística, Ministério do Planejamento Orçamento e Gestáo. Pesquisa Nacional por amostra de domicílios tabagismo. Rio de Janeiro: Ministério da Saúde; 2009.

15. UNODC. Gratefully acknowledges the contribution of the Government of Austria towards the cost of the World Drug Report. Austria; 2011.

16. Ribeiro M, Dunn J, Sesso R, Dias AC, Laranjeira R. Causes of death among crack cocaine users. Rev Bras Psiquiatr. 2006 Set;28(3):196-202.

17. Oliveira LG, Nappo SA. Caracterizaçáo da cultura de crack na cidade de São Paulo: padrão de uso controlado. Rev Saúde Pública. 2008 Jul;42(4):664-71.

18. Duailibi LB, Ribeiro M, Laranjeira R. Profile of cocaine and crack users in Brazil. Cad Saúde Pública. 2008;24(sup.4):545-57.

19. Ribeiro LA, Sanchez Z M, Nappo SA. Estratégias desenvolvidas por usuários de crack para lidar com os riscos decorrentes do consumo da droga. J Bras Psiquiatr. $2010 \mathrm{Jul} /$ Set;59(3):210-8.

20. Jorge JS, Webster CMC. Consultório de rua: contribuições e desafios de uma prática em construçâo. Sau $\&$ Transf Soc. 2012;3(1):39-48.

21. Silva SM. A unidade de redução de danos do município de Santo André: uma avaliação [Dissertação]. São Paulo: Escola de Enfermagem da Universidade de Sáo Paulo; 2008.

22. Pereira A, Wurfel RF. O uso de maconha como estratégia de reduçáo de danos em dependentes de crack. Aletheia. 2011;34:163-74.

23. Bardin L. Análise de conteúdo. Lisboa: Ediçôes 70 LDA; 2009.

24. Brasil, Ministério da Saúde, Núcleo Técnico da Política Nacional de Humanização. HumanizaSUS: Política
Nacional de Humanização: a humanização como eixo norteador das práticas de atenção e gestão em todas as instâncias do SUS. Brasília: Ministério da Saúde; 2004.

25. Paes PCD. Ensino aprendizagem na prática da redução de danos [Tese]. São Carlos: Universidade Federal de São Carlos; 2006.

26. Brasil, Ministério da Saúde, Secretaria de Atenção à Saúde, Departamento de Ações Programáticas Estratégicas. Saúde mental no SUS: os centros de atenção psicossocial. Brasília: Ministério da Saúde; 2004.

27. Brasil, Ministério da Saúde, Coordenação Nacional de Saúde Mental. Consultórios de Rua do SUS. Material de trabalho para a II Oficina Nacional de Consultórios de Rua do SUS.Brasília: Ministério da Saúde; Convênio Escola Politécnica Joaquim Venâncio; 2010.

28. Santos GL. Um estudo do perfil das dependentes químicas, usuárias do centro de atendimento psicossocial álcool e drogas - CAPSad do Município de Caçador [Trabalho conclusão de curso]. Caçador: Universidade do Alto Vale do Rio do Peixe; 2010.

29. Santos MA, Pratta EMM. Adolescência e uso de drogas à luz da psicanálise: sofrimento e êxtase na passagem.Tempo psicanal.2012;44(1):167-82.

30. Morais $\mathrm{M}$. O modelo de atenção integral à saúde para tratamento de problemas decorrentes do uso de álcool e outras drogas: percepçóes de usuários, acompanhantes e profissionais. Ciên \& Saúde Col. 2008 Jan/Fev;13(1):121-33.

31. Brasil. Ministério da Saúde Portaria n 1.059/ GM, de 4 de julho de 2005. Destina incentivo financeiro para o fomento de açóes de resuçáo de danos em Centros de Atençáo Psicossocial para o Álcool e outras Drogas - CAPSad - e dá outras providências.

32. Institute of Medicine of the National Academy of Sciences. Preventing HIV Infection among injecting drug users in high risk countries: an assessment of evidence [Internet]. Washington DC: IOM; 2006 [acesso em 2013 Abr 14]. Disponível em: http://www.iom.edu/ /media/Files/ Report\%20Files/2006/

33. Wodak A, Cooney A. Do needle syringe programs reduce HIV infection among injecting drug users: a comprehensive review of the international evidence.Subs Use Misuse. 2006 Fev;41(6-7):777-813.

34. Vargas D, Bittencourt MN, Rocha FM, Oliveira MAF. Representaçáo social de enfermeiros de centros de atençáo psicossocial em álcool e drogas (Capsad) sobre o dependente químico. Esc Anna Nery. 2013 Abr/Jun;17(2):242-8.

35. Vargas D, Oliveira MAF, Luis MV. Atendimento ao alcoolista em serviços de atenção primária à saúde: percepçóes e condutas do enfermeiro. ActaPaul Enferm. 2010 Jan/ Fev;23(1):73-9.

36. Sampaio JJC, Guimarães JMX, Carneiro C, Filho CG. O trabalho em serviços de saúde mental no contexto da reforma psiquiátrica: um desafio técnico, político e ético. CiêncSaúde Coletiva. 2011 Dez;16(12):4685-94. 
37. Santos VE, Soares CB, Campos CMS. Reduçáo de danos: análise das concepçóes que orientam as práticas no Brasil. Physis.2010 Jul/Set;20(3):995-1015.

38. Vasconcelos SC, Frazão IS, Vasconcelos EMR, Cavalcanti AMTS, Monteiro EMLM, Ramos VP. Demandas de autocuidado em grupo terapêutico: educação em saúde com usuários de substâncias psicoativas. Rev Enferm UERJ. 2013;21(1):79-83.

39. Oliveira LMAC, Medeiros M, BrasilVV, Oliveira PMC, Munari DB. Uso de fatores terapêuticos para avaliação de resultados em grupos de suporte. Acta Paul Enferm. 2008 $\mathrm{Jul} / \mathrm{Set} ; 21(3): 432-8$.

40. Alvarez SQ, Gomes GC, Oliveira AMN, Xavier DM. Grupo de apoio/suporte como estratégia de cuidado: importância para familiares de usuários de drogas. Rev Gaúcha Enferm. 2012 Jun;33(2):102-8.

41. Giaretta A, Ghiorzi AR. O ato de comer e as pessoas com síndrome de Down. RevBras Enferm. 2009 Mai/ Jun;62(3):480-4. 